Published in final edited form as:

J Am Chem Soc. 2020 February 05; 142(5): 2592-2600. doi:10.1021/jacs.9b12689.

\title{
Emissive Platinum(II) Cages with Reverse Fluorescence Resonance Energy Transfer for Multiple Sensing
}

\section{Zeyuan Zhang",}

State Key Laboratory for Mechanical Behavior of Materials, Shaanxi International Research Center for Soft Matter, School of Materials Science and Engineering, Xi'an Jiaotong University, Xi'an 710049, P. R. China

\section{Zhengqing Zhao\#,}

State Key Laboratory for Mechanical Behavior of Materials, Shaanxi International Research Center for Soft Matter, School of Materials Science and Engineering, Xi'an Jiaotong University, Xi'an 710049, P. R. China

\section{Lianwei Wu,}

State Key Laboratory of Superhard Materials, College of Physics, Jilin University, Changchun 130012, P. R. China

\section{Shuai Lu,}

Department of Chemistry, University of South Florida, Tampa, Florida 33620, United States; College of Chemistry, Zhengzhou University, Zhengzhou 450001, P. R. China

\section{Sanliang Ling,}

Advanced Materials Research Group, Faculty of Engineering, University of Nottingham, Nottingham NG7 2RD, United Kingdom

\section{Guoping Li,}

Frontier Institute of Science and Technology, Xi'an Jiaotong University, Xi'an 710049, P. R. China

\section{Letian Xu,}

Frontier Institute of Science and Technology, Xi'an Jiaotong University, Xi'an 710049, P. R. China

\section{Lingzhi Ma,}

State Key Laboratory for Mechanical Behavior of Materials, Shaanxi International Research Center for Soft Matter, School of Materials Science and Engineering, Xi'an Jiaotong University, Xi'an 710049, P. R. China

\section{Yali Hou,}

\footnotetext{
Corresponding AuthorsKai Wang kaiwang@jlu.edu.cn; Mingming Zhang mingming.zhang@xjtu.edu.cn.

\#Author Contributions

These authors contributed equally to this work.

Supporting Information

The Supporting Information is available free of charge at https://pubs.acs.org/doi/10.1021/jacs.9b12689.

Syntheses and characterization data (NMR and fluorescence spectra), including Figures S1-S62 (PDF)

The authors declare no competing financial interest.
} 
State Key Laboratory for Mechanical Behavior of Materials, Shaanxi International Research Center for Soft Matter, School of Materials Science and Engineering, Xi'an Jiaotong University, Xi'an 710049, P. R. China

\section{Xingchen Wang,}

State Key Laboratory for Mechanical Behavior of Materials, Shaanxi International Research Center for Soft Matter, School of Materials Science and Engineering, Xi'an Jiaotong University, Xi'an 710049, P. R. China

\section{Xiaopeng Li,}

Department of Chemistry, University of South Florida, Tampa, Florida 33620, United States

\section{Gang He,}

Frontier Institute of Science and Technology, Xi'an Jiaotong University, Xi'an 710049, P. R. China

\section{Kai Wang,}

State Key Laboratory of Superhard Materials, College of Physics, Jilin University, Changchun 130012, P. R. China

\section{Bo Zou,}

State Key Laboratory of Superhard Materials, College of Physics, Jilin University, Changchun 130012, P. R. China

\section{Mingming Zhang}

State Key Laboratory for Mechanical Behavior of Materials, Shaanxi International Research Center for Soft Matter, School of Materials Science and Engineering, Xi'an Jiaotong University, Xi'an 710049, P. R. China

\section{Abstract}

It is quite challenging to realize fluorescence resonance energy transfer (FRET) between two chromophores with specific positions and directions. Herein, through the self-assembly of two carefully selected fluorescent ligands via metal-coordination interactions, we prepared two tetragonal prismatic platinum(II) cages with a reverse FRET process between their faces and pillars. Bearing different responses to external stimuli, these two emissive ligands are able to tune the FRET process, thus making the cages sensitive to solvents, pressure, and temperature. First, these cages could distinguish structurally similar alcohols such as $n$-butanol, $t$-butanol, and $i$ butanol. Furthermore, they showed decreased emission with bathochromic shifts under high pressure. Finally, they exhibited a remarkable ratiometric response to temperature over a wide range (223-353 K) with high sensitivity. For example, by plotting the ratio of the maximum emission $\left(I_{600} / I_{480}\right)$ of metallacage $4 \mathbf{b}$ against the temperature, the slope reaches 0.072 , which is among the highest values for ratiometric fluorescent thermometers reported so far. This work not only offers a strategy to manipulate the FRET efficiency in emissive supramolecular coordination complexes but also paves the way for the future design and preparation of smart emissive materials with external stimuli responsiveness.

\section{Graphical Abstract}




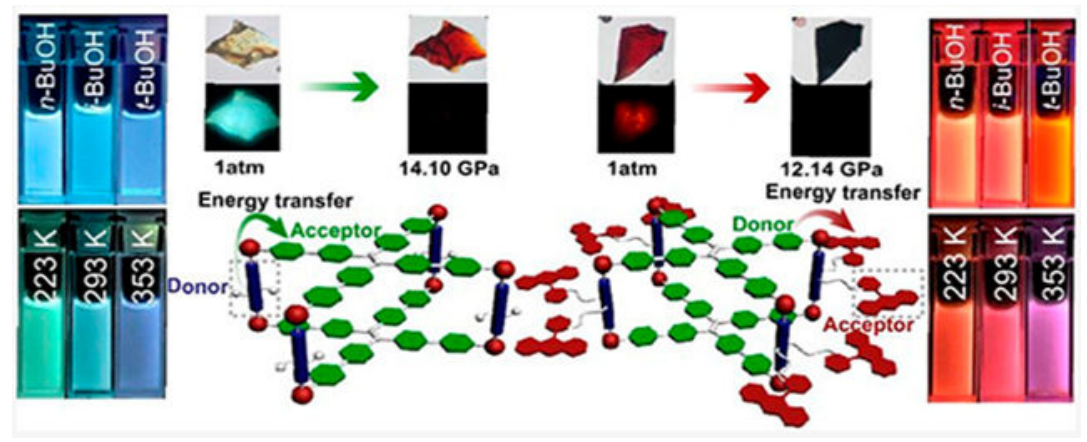

\section{INTRODUCTION}

Energy transfer is of vital importance within many significant processes including the combustion of matter, the generation of electricity, and photosynthesis. Fluorescence (or Förster) resonance energy transfer (FRET) describes the energy transfer between different chromophores through nonradiative dipole-dipole coupling. ${ }^{1}$ A well-known FRET system is the energy transfer from carotenoids to chlorophyll in natural photosynthesis, ${ }^{2}$ which is considered to be the most important chemical reaction on earth. Efficient FRET requires a suitable distance between the energy donors and acceptors as well as good spectral overlap between the emission of the donors and the excitation of the acceptors. ${ }^{3}$ Compared to covalently linked systems, FRET systems formed via noncovalent interactions not only afford a convenient method to avoid time-consuming synthesis but also reduce the possibility of emission changes caused by covalent functionalization. ${ }^{4}$ Therefore, various FRET-based supramolecular systems have been designed along with exploration in biomimicry, ${ }^{5}$ bioimaging, ${ }^{6}$ light-emitting materials, ${ }^{7}$ and photocatalysis ${ }^{8}$ during the past two decades.

Self-assemblies formed by coordination bonds, including metal-organic frameworks $(\mathrm{MOFs})^{9}$ and supramolecular coordination complexes (SCCs), ${ }^{10}$ have become one of the most important themes in supramolecular materials during the past three decades. Abundant SCCs with fascinating structures ${ }^{11}$ have been successfully constructed for guest encapsulation, catalysis, sensing, and stabilizing reactive intermediates. ${ }^{12}$ Compared to other noncovalent interactions, metal-coordination interactions are still effective even at micromolar or even nanomolar concentrations, ${ }^{13}$ while for hydrogen bonding and host-guest interactions the complexes dissociate dramatically upon dilution due to their low association constants for common systems. ${ }^{14}$ Therefore, metal-coordination interactions show great advantages in preparing effective FRET systems, especially because the study of the FRET process should also be performed at the micromolar or even nanomolar concentration level to reduce the influence of molecular aggregation. Some successful examples can be found in MOF-based systems ${ }^{15}$ in which two different chromophores are properly manipulated to achieve efficient FRET to mimic the light-harvesting process in photosynthesis. However, the poor solubility and stability of MOFs in common solvents limit their processability for further applications. Although the preparation of SCCs offers an alternative way to solve this problem, metallacycles and metallacages with efficient FRET have rarely been reported ${ }^{16}$ due to the difficulties in the design and synthesis of two compatible chromophores with ideal 
spectral overlap as well as the quenching of emission by transition metals (also known as the heavy atom effect). ${ }^{17}$

In order to solve the heavy atom effect, Stang ${ }^{18}$ and others ${ }^{19}$ referred to the concept of aggregation-induced emission (AIE) ${ }^{20}$ raised by Tang et al. and developed coordinationinduced emission. For AIE-based systems, the fluorophores emit strongly at high concentration or in the aggregation state but are nearly nonemissive in dilute solution. In most of the AIE-based fluorophores, propeller-like structures offer a pathway for molecular motion to deactivate the molecules in the excited state in dilute solution through thermal decay. In the aggregation state, the molecular motion is restricted due to molecular aggregation, thus reducing the nonradiative decay to give bright emission. In coordinationinduced emission-based systems, the motion of the molecules is restricted by coordination bonds, instead of molecular aggregation in AIE-based systems, to give strong emission. A series of emissive metallacycles and metallacages were prepared on the basis of tetraphenylethene (TPE) for chemical sensing, ${ }^{21}$ light emitting, ${ }^{22}$ and light-harvesting materials. ${ }^{23}$ However, the FRET process within these structures remains unexplored. Herein, through the careful functionalization of the pillar parts of TPE-based tetragonal prismatic platinum(II) cages, ${ }^{21 \mathrm{~b}}$ we are able to efficiently control the FRET either from the pillars to the faces (cage 4a) or from the faces to the pillars (cage $\mathbf{4 b}$ ). Moreover, because the faces (1) are an AIE fluorophore while the pillars (2a and $\mathbf{2 b}$ ) are aggregation-caused quenching (ACQ) fluorophores ${ }^{20}$ as well as their structural differences, they show different responses to temperature, mechanical pressure, and solvent composition and polarity. Such different responses further affect the spectral overlap between the energy donors and acceptors, making metallacages $\mathbf{4 a}$ and $\mathbf{4 b}$ very sensitive to environmental changes. Therefore, metallacages $4 \mathbf{a}$ and $\mathbf{4 b}$ can act as sensors for temperature, pressure, and solvents. This study not only offers a convenient method to prepare SCCs with efficient energy transfer but also explores their application toward probing and sensing, which will facilitate the development of stimuli-responsive light-emitting materials.

\section{RESULTS AND DISCUSSION}

\section{Design, Preparation, and Characterizations of Metallacages.}

On the basis of a previous study, ${ }^{21 \mathrm{~b}}$ the TPE-based benzoate ligand (1), which acts as the faces of the tetragonal prismatic metallacages, generally absorbs in the UV region (250-400 $\mathrm{nm}$ ) and shows a maximum emission in the range of 480-500 nm. If TPE faces act as the acceptor within the cage, then the pillar parts as the donor should emit near the UV region to achieve efficient FRET. However, if TPE faces behave as the donor within the cage, then the pillar parts as the acceptor should possess an obvious absorption band at ca. 480-500 nm. Moreover, the pillar molecules should be $180^{\circ}$ dipyridyl ligands with a rigid configuration to meet the requirements for directional self-assembly. On the basis of these principles, we designed two metallacages with distinct FRET behaviors. First, compound 2a with a strong emission band centered at $422 \mathrm{~nm}$ was chosen as the donor to prepare metallacage 4a to study the FRET from the pillars to the faces (Scheme 1). Second, rhodamine B, a wellknown fluorophore which shows an intense absorption band from 450 to $600 \mathrm{~nm}$ and a high quantum yield, was linked to the pillar parts to prepare compound $\mathbf{2 b}$ as the energy acceptor 
to achieve efficient FRET from the faces to the pillars within metallacage $4 \mathbf{b}$. These two metallacages possess reverse FRET process either from the pillars to the faces $(\mathbf{4 a})$ or from the faces to the pillars (4b), which greatly influences their photophysical properties.

The preparation of metallacages $\mathbf{4 a}$ and $\mathbf{4 b}$ is depicted in Scheme 1. On the basis of the selfassembly of TPE-based ligand $\mathbf{1}$, dipyridyl ligands $\mathbf{2 a}$ or $\mathbf{2} \mathbf{b}$, and cis-Pt $\left(\mathrm{PEt}_{3}\right)_{2}(\mathrm{OTf})_{2} \mathbf{3}$ in a 1:2:4 molar ratio, metallacages $\mathbf{4 a}$ and $\mathbf{4 b}$ were synthesized in good yields (Scheme 1). The structures of metallacages $4 \mathbf{a}$ and $\mathbf{4 b}$ were evidenced by ${ }^{31} \mathrm{P}\left\{{ }^{1} \mathrm{H}\right\}$ NMR and ${ }^{1} \mathrm{H}$ NMR spectroscopy and electrospray ionization time-of-flight mass spectroscopy (ESI-TOF MS). It can be seen from Figure 1 (spectra a-c) that the ${ }^{31} \mathrm{P}\left\{{ }^{1} \mathrm{H}\right\}$ NMR spectra of the two metallacages split into two doublet peaks at 5.53 and $0.40 \mathrm{ppm}$ for $\mathbf{4 a}$ and at 5.69 and 0.63 ppm for $\mathbf{4 b}$, respectively. The two peaks are of equal intensity with concomitant ${ }^{195} \mathrm{Pt}$ satellites because each platinum atom coordinates with one nitrogen atom of the pyridyl group in the pillar and one oxygen atom of the carboxylic group in the face, forming chargeseparated complexes. In the ${ }^{1} \mathrm{H}$ NMR spectra (Figure 1, spectra $\mathrm{f}-\mathrm{i}$ ), $\boldsymbol{a}$-pyridyl protons $\mathrm{H}_{1}$ (for $\mathbf{4 a}$ ) and $\mathrm{H}_{5}$ (for $\mathbf{4 b}$ ) and $\beta$-pyridyl protons $\mathrm{H}_{2}$ (for $\mathbf{4 a}$ ) and $\mathrm{H}_{6}$ (for $\mathbf{4 b}$ ) shifted downfield compared to their uncoordinated precursors $\mathbf{2} \mathbf{a}$ and $\mathbf{2 b}$. It is worth noting that some protons $\left(\mathrm{H}_{5}, \mathrm{H}_{8}, \mathrm{H}_{9}\right.$, and $\left.\mathrm{H}_{17}\right)$ on cage $\mathbf{4 b}$ split into two sets of signals because the functionalization of cages on the pillar parts reduced the symmetry of the cage, giving two different types of chemical environments for the protons. ESI-TOF gives evidence of the coordination stoichiometry of metallacage $\mathbf{4 a}$ and $\mathbf{4 b}$ by showing peaks at $\mathrm{m} / z 1336.88$ and 2304.41 (Figure 1, spectra $\mathrm{d}$ and e), corresponding to $[\mathrm{M}-5 \mathrm{OTf}]^{5+}$ species of $\mathbf{4 a}$ and $\mathbf{4 b}$, respectively. All of these observations are consistent with previous reports, ${ }^{23 a}$ indicating the formation of tetragonal prisms.

Since all attempts to obtain the crystal structures of metallacages $4 \mathbf{a}$ and $\mathbf{4 b}$ were unsuccessful, density functional theory (DFT) calculations (see Supporting Information for computational details) were performed in order to gain insight into the structures of metallacages $\mathbf{4 a}$ and $\mathbf{4 b}$ (Figure 2). The tetragonal prismatic structures were formed with TPE units as the faces, dipyridyl moieties as the pillars, and $90^{\circ} \mathrm{Pt}(\mathrm{II})$ ions as the corners, respectively. The DFT-optimized structure of cage $\mathbf{4 b}$ shows that rhodamine groups possess two different conformations due to the steric hindrance, which causes some of the protons to split into two sets of peaks in the ${ }^{1} \mathrm{H}$ NMR spectra (Figure 1i). The DFT-optimized structures of cages $\mathbf{4 a}$ and $\mathbf{4 b}$ reveal diameters of 4.18 and $5.50 \mathrm{~nm}$, respectively. The TPE groups are partially rigidified, and the molecular rotation of the aromatic rings is limited by the metal-coordination bonds, endowing the cages with emission properties.

\section{Photophysical Studies.}

The photophysical properties of the individual components were first investigated to reveal their potential for FRET. (See the Supporting Information for details.) As shown in Figure 3a, the absorption spectrum of TPE-based ligand 1 well overlaps with the emission spectrum of compound 2a. Similar overlap (Figure 3d) was also observed for the absorption of compound $\mathbf{2 b}$ and the emission of $\mathbf{1}$. After the formation of the metallacages, the distance between the pillars and the faces is significantly shortened (Figure 2), offering an electronic pathway to enable the FRET process because of the increased dipole-dipole coupling. It can 
be seen clearly from the fluorescence titration experiments (Figure $3 b, e$ ) that with the gradual addition of the acceptors into the solution of donors and cis- $-\mathrm{Pt}\left(\mathrm{PEt}_{3}\right)_{2}(\mathrm{OTf})_{2}(\mathbf{3})$, the emission of the donors decreased and that of the acceptors increased. Moreover, the fluorescence intensity remained almost unchanged when the ratios between the donors and acceptors reached their stoichiometries (Figure $3 \mathrm{c}, \mathrm{f}$ ). These experiments suggested the efficient energy transfer between the pillars and faces in metallacages $\mathbf{4 a}$ and $\mathbf{4 b}$. Because the face molecule (TPE-based ligand $\mathbf{1}$ ) is an AIE-active fluorophore and the pillar molecules (2a and $\mathbf{2 b}$ ) are ACQ fluorophores as well as their structural differences, their responses to the solvent compositions, mechanical pressure, and temperature differ greatly. This makes it possible to change the degree of spectral overlap between the emission of the donors and the absorption of the acceptors under the aforementioned stimuli, thereby change the efficiency of FRET in metallacages $\mathbf{4 a}$ and $\mathbf{4 b}$. Therefore, the emission of metallacages $4 \mathbf{a}$ and $\mathbf{4 b}$ could be very sensitive to the solvent composition, mechanical pressure, and temperature, making them good candidates as chemical sensors.

\section{Solvatochromic Properties.}

To understand the effect of different solvents on the photophysical properties, we first measured the UV-vis absorption (Figure S13) and emission spectra (Figure S14) of metallacages $\mathbf{4 a}$ and $\mathbf{4 b}$ in several commonly used solvents. Metallacage $4 \mathbf{a}$ shows an intense absorption peak centered at ca. $292 \mathrm{~nm}$ with a shoulder at ca. $356 \mathrm{~nm}$ in almost all of the tested solvents, while metallacage $\mathbf{4 b}$ exhibits an extra intense absorption peak at ca. 565 $\mathrm{nm}$, which comes from the absorption of rhodamine moieties. However, the emission of these two cages differs a lot in different solvents (Figure S14). For example, metallacage 4a shows only one major peak centered at $460 \mathrm{~nm}$ in dichloromethane but exhibits two intense emission peaks centered at ca. $412-426$ and $462-485 \mathrm{~nm}$ in acetone, acetonitrile, chloroform, DMF, and DMSO. Metallacage $4 \mathbf{b}$ exhibits two emission peaks at around 470 and $605 \mathrm{~nm}$ in dichloromethane, chloroform, DMF, and DMSO while showing almost one peak at ca. $600 \mathrm{~nm}$ in acetone and acetonitrile. Factors which may contribute to the vast differences in the emission of our metallacages in different solvents may include (1) the different emission behaviors of the faces with AIE and the pillars with ACQ, (2) the different solubilities of the metallacages in different solvents, and (3) the different FRET efficiencies in different solvents (Figure S16).

The sensitivity of metallacages toward different solvents inspired us to explore the use of their emission to distinguish structurally similar alcohols. The stability of the metallacages was first studied. The ${ }^{31} \mathrm{P}\left\{{ }^{1} \mathrm{H}\right\}$ NMR and ${ }^{1} \mathrm{H}$ NMR spectra (Figures S17) of metallacage 4a in methanol is unchanged upon the addition of different alcohols including ethanol (EtOH), $t$-butanol $(t-\mathrm{BuOH})$, and ethyl glycol, indicating that the cages are chemostable in common alcohols. As shown in Figure 4, the maximum emission and the intensity of the cages are different in the tested alcohols. Metallacage 4a shows maximum emission centered at 439, 440 , and $414 \mathrm{~nm}$ in $n$-butanol, $i$-butanol, and $t$-butanol, respectively (Figure 4a). For metallacage $4 \mathrm{~b}$, the alcohols could be distinguished by the ratio of their two emission bands (Figure 4b). Both cages show different Commission Internationale de l'Éclairage (CIE) chromaticity coordinates in the three structurally similar alcohols (Figure 4c). Among the three types of $\mathrm{BuOH}, t-\mathrm{BuOH}$ can be easily distinguished from $n / i-\mathrm{BuOH}$ by the naked eye 
due to their color differences (insets of Figure 4a,b). With the help of CIE chromaticity coordinates, the three types of alcohols can be readily distinguished. We note that the emission energy of $\mathbf{4 a}$ in $t-\mathrm{BuOH}$ is different from that in $n / \mathrm{i}-\mathrm{BuOH}$, perhaps due to different solvent polarity (Table S3). On the other hand, the emission energies of $\mathbf{4 b}$ in different solvents are the same, which may be associated with the different characteristics of the lowest excited states of $\mathbf{4 a}$ and $\mathbf{4 b}$ (Figure S22). Furthermore, the different emission intensities of $\mathbf{4 a}$ and $\mathbf{4 b}$ in different solvents could be attributed to the different solvent viscosities (Table S3); more viscous solvent (e.g., $t-\mathrm{BuOH}$ ) tends to show higher emission intensity due to suppressed collisions between fluorescent molecules with less energy lost (as heat) through nonradiative decay.

\section{Mechanochromic Properties.}

Mechanochromic materials which change their emission in response to external forces have been widely used in fluorescent switches and devices. ${ }^{24}$ Although the piezofluorochromic properties of TPE-based small molecules ${ }^{25}$ and $\mathrm{MOFs}^{26}$ have been intensively studied, the mechanochromic response of TPE-based metallacages has been rarely addressed. In order to study the structural response under high pressure, the fluorescence upon stress was collected in situ with a diamond anvil cell technique. ${ }^{27}$ Metallacages $\mathbf{4 a}$ and $\mathbf{4 b}$ show light-green and deep-red emission with maximum emission at ca. 500 and $605 \mathrm{~nm}$, respectively, under ambient conditions. Upon compression, the photoluminescence maximum of metallacages 4a and $4 \mathbf{b}$ experienced a large bathochromic shift to $620 \mathrm{~nm}$ at $14.1 \mathrm{GPa}$ and to $700 \mathrm{~nm}$ at $12.1 \mathrm{GPa}$, respectively. Moreover, the emission intensity decreased significantly as the pressure increased, and the whole process was fully reversible at least for 10 cycles (Figure S52). We speculate that the mechanochromic response of our metallacages is due to tighter molecular packing resulting from the mechanical compression, and as a result, the pillars become tilted and the TPE faces become more planarized, affecting the dipole-dipole coupling between the pillars and the faces and therefore the emission wavelength and intensity. We note that a similar mechanochromic response was also observed in TPEcontaining MOF-based systems ${ }^{26}$ and AIE-fluorophore-based cocrystals. ${ }^{28}$

\section{Thermochromic Property.}

Temperature-responsive luminescent materials with two different emission bands can act as ratiometric fluorescent thermometers to improve the accuracy and precision via selfcalibration. ${ }^{29}$ In metallacages $\mathbf{4 a}$ and $\mathbf{4 b}$, two fluorophores which may display different responses to the temperature were incorporated, and the temperature change was expected to influence the efficiency of FRET. This motivated us to further study their response toward temperature changes. DMF was chosen as the solvent because it can be used over a wide range of temperature based on its low freezing point $\left(-61^{\circ} \mathrm{C}\right)$ and high boiling point (153 $\left.{ }^{\circ} \mathrm{C}\right)$. The NMR spectra recorded for cages $\mathbf{4 a}$ and $\mathbf{4 b}$ in DMF- $d_{7}$ are similar to the spectra in acetone- $d_{6}$, indicating that they are chemostable in DMF (Figures S53-S61). As shown in Figure $6 \mathrm{a}$, as the temperature increased, the emission at $425 \mathrm{~nm}$ corresponding to the donor increased, while the emission at $488 \mathrm{~nm}$ that is ascribed to the acceptor decreased for metallacage 4a upon excitation at $340 \mathrm{~nm}$. A linear fitting curve (slope $=-0.006$ ) of $I_{488} / I_{425}$ versus temperature (Figure $6 \mathrm{c}$ ) was plotted, indicating that metallacage $4 \mathbf{a}$ may serve as a 
fluorescent thermometer in the range from 223 to $353 \mathrm{~K}$. Similar to metallacage $\mathbf{4 a}$, increased donor emission at $480 \mathrm{~nm}$ and decreased acceptor emission at $600 \mathrm{~nm}$ were observed for $\mathbf{4 b}$ with increases in temperature. The ratio of the maximum emission $\left(I_{600} /\right.$ $I_{480}$ ) also decreased linearly with the temperature in the range from 233 to $333 \mathrm{~K}$.

Remarkably, the absolute value of the slope is 0.072 , which is among the highest values for ratiometric fluorescent thermometers reported so far. ${ }^{29}$ This indicates that the increase in temperature can decrease the efficiency of FRET, perhaps due to the partial dissociation of the metal-coordination bonds at high temperature.

Encouraged by the fluorescence changes in the metallacages along with temperature in solution, ${ }^{30}$ two thin films were prepared by doping the metallacages into poly(vinylidene fluoride) (PVDF). Although no obvious color changes were observed from the optical photographs of the films at different temperatures, their fluorescent photographs differ dramatically at different temperatures (Figure $6 \mathrm{~g}, \mathrm{~h}$ ). The whole process is fully reversible after 10 cycles, indicating that the metallacages can serve as good sensors for temperature. Different from most fluorescent thermometers that are prepared solely on the basis of the intensity changes, our system offers an approach to manipulating two fluorophores with efficient FRET in a single supramolecular system to prepare ratiometric thermometers, which will pave the way for future design of fluorescent thermometers.

\section{CONCLUSIONS}

Two tetragonal prismatic platinum(II) cages with reverse energy transfer between their pillars and faces were prepared and characterized by ${ }^{31} \mathrm{P}$ NMR and ${ }^{1} \mathrm{H}$ NMR spectroscopy, ESI-TOF-MS, UV-vis absorption, and fluorescence spectros-copy. Because of the different fluorescence properties of the two ligands, they show different responses to external stimuli including solvent polarity, composition, pressure, and temperature, which significantly change the efficiency of FRET, thus influencing the emission of the cages. Their use in distinguishing structurally similar alcohols and as fluorescent ratiometric thermometers was explored, showing their potential applications as highly sensitive chemical sensors. This study not only provides a type of metal-coordinated structure in which the efficiency of FRET can be finely tuned between their building blocks but also takes advantage of such a response to explore their practical applications for chemical and temperature sensing. As such, it will open up a new avenue for stimuli-responsive and light-emitting materials, sensors, and bioimaging.

\section{Supplementary Material}

Refer to Web version on PubMed Central for supplementary material.

\section{ACKNOWLEDGMENTS}

This work was supported by the National Natural Science Foundation of China (21801203 to M.Z., 11774120 to K.W., and 21725304 to B.Z.), the National Institutes of Health (R01GM128037 to X.L.), and The Key Research and Development Program of Shaanxi Province (2019KW-019 to M.Z.). M.Z. is thankful for start-up funds from Xi' an Jiaotong University. We thank Dr. Gang Chang and Yu Wang at the Instrument Analysis Center and Dr. Aqun Zheng and Junjie Zhang at the Experimental Chemistry Center of Xi' an Jiaotong University for NMR and fluorescence measurements. 


\section{REFERENCES}

(1) (a). Förster T Zwischenmolekulare Energiewanderung und Fluoreszenz. Ann. Phys 1948, 437, 5575.(b)Förster T Transfer Mechanisms of Electronic Excitation. Discuss. Faraday Soc. 1959, 27, $7-17$.

(2). Mirkovic T; Ostroumov EE; Anna JM; van Grondelle R; Govindjee; Scholes GD, Light Absorption and Energy Transfer in the Antenna Complexes of Photosynthetic Organisms. Chem. Rev 2017, 117, 249-293. [PubMed: 27428615]

(3). Peng H-Q; Niu L-Y; Chen Y-Z; Wu L-Z; Tung C-H; Yang Q-Z Biological Applications of Supramolecular Assemblies Designed for Excitation Energy Transfer. Chem. Rev 2015, 115 , 7502-7542. [PubMed: 26040205]

(4). Teunissen AJP; Perez-Medina C; Meijerink A; Mulder WJM Investigating Supramolecular Systems Using Förster Resonance Energy Transfer. Chem. Soc. Rev 2018, 47, 7027-7044. [PubMed: 30091770]

(5) (a). Peng H-Q; Chen Y-Z; Zhao Y; Yang Q-Z; Wu L-Z; Tung C-H; Zhang L-P; Tong Q-X Artificial Light-Harvesting System Based on Multifunctional Surface-Cross-Linked Micelles. Angew. Chem., Int. Ed 2012, 51, 2088-2092.(b)Xu Z; Peng S; Wang Y-Y; Zhang J-K; Lazar AI; Guo D-S Broad-Spectrum Tunable Photoluminescent Nanomaterials Constructed from a Modular LightHarvesting Platform Based on Macrocyclic Amphiphiles. Adv. Mater 2016, 28, 7666-7671. [PubMed: 27346287] (c)Chen P-Z; Weng YX; Niu L-Y; Chen Y-Z; Wu L-Z; Tung C-H; Yang QZ Light-Harvesting Systems Based on Organic Nanocrystals to Mimic Chlorosomes. Angew. Chem., Int. Ed 2016, 55, 2759-2763.(d)Guo S; Song Y; He Y; Hu X-Y; Wang L Highly Efficient Artificial Light-Harvesting Systems Constructed in Aqueous Solution Based on Supramolecular Self-Assembly. Angew. Chem. Int. Ed 2018, 57, 3163-3167.

(6) (a). Mu J; Liu F; Rajab MS; Shi M; Li S; Goh C; Lu L; Xu Q-H; Liu B; Ng LG; Xing B A SmallMolecule FRET Reporter for the Real-Time Visualization of Cell-Surface Proteolytic Enzyme Functions. Angew. Chem., Int. Ed 2014, 53, 14357-14362(b)Jia X; Chen Q; Yang Y; Tang Y; Wang R; Xu Y; Zhu W; Qian X FRET-Based Mito-Specific Fluorescent Probe for Ratiometric Detection and Imaging of Endogenous Peroxynitrite: Dyad of Cy3 and Cy5. J. Am. Chem. Soc 2016, 138, 10778-10781. [PubMed: 27517310] (c)Tian M; Ma Y; Lin W Fluorescent Probes for the Visualization of Cell Viability. Acc. Chem. Res 2019, 52, 2147-2157. [PubMed: 31335119]

(7) (a). Abbel R; Grenier C; Pouderoijen MJ; Stouwdam JW; Leclère PELG; Sijbesma RP; Meijer EW; Schenning APHJ White-Light Emitting Hydrogen-Bonded Supramolecular Copolymers Based on $\pi$-Conjugated Oligomers. J. Am. Chem. Soc 2009, 131, 833-843. [PubMed: 19093865] (b)Vijayakumar C; Praveen VK; Ajayaghosh A RGB Emission through Controlled Donor SelfAssembly and Modulation of Excitation Energy Transfer: A Novel Strategy to White-LightEmitting Organogels. Adv. Mater 2009, 21, 2059-2063.(c)Praveen VK; Ranjith C; Armaroli N White-Light-Emitting Supramolecular Gels. Angew. Chem., Int. Ed 2014, 53, 365-368.

(8) (a). Wang F; Wang W-G; Wang H-Y; Si G; Tung C-H; Wu L-Z Artificial Photosynthetic Systems Based on FeFe-Hydrogenase Mimics: The Road to High Efficiency for Light-Driven Hydrogen Evolution. ACS Catal 2012, 2, 407-416.(b)Hao M; Sun G; Zuo M; Xu Z; Chen Y; Hu X-Y; Wang L A Supramolecular Artificial Light-harvesting System with Two-step Sequential Energy Transfer for Photochemical Catalysis. Angew. Chem., Int. Ed 2019, 58, DOI: 10.1002/ anie.201912654.

(9) (a). Horike S; Shimomura S; Kitagawa S Soft Porous Crystals. Nat. Chem 2009, 1, 695-704. [PubMed: 21124356] (b)Zhou H-C; Long JR; Yaghi OM Introduction to Metal-Organic Frameworks. Chem. Rev 2012, 112, 673-674. [PubMed: 22280456] (c)Furukawa H; Cordova KE; O'Keeffe M; Yaghi OM The Chemistry and Applications of Metal-Organic Frameworks. Science 2013, 341, 1230444. [PubMed: 23990564]

(10) (a). Cook TR; Zheng Y-R; Stang PJ Metal-Organic Frameworks and Self-Assembled Supramolecular Coordination Complexes: Comparing and Contrasting the Design, Synthesis, and Functionality of Metal-Organic Materials. Chem. Rev 2013, 113, 734-777. [PubMed: 23121121] (b)Brown CJ; Toste FD; Bergman RG; Raymond KN Supramolecular Catalysis in Metal-Ligand Cluster Hosts. Chem. Rev 2015, 115, 3012-3035. [PubMed: 25898212] (c)Cook TR; Stang PJ Recent Developments in the Preparation and Chemistry of Metallacycles and Metallacages via 
Coordination. Chem. Rev 2015, 115, 7001-7045. [PubMed: 25813093] (d)Wang W; Wang Y-X; Yang H-B Supramolecular Transformations within Discrete Coordination-Driven Supramolecular Architectures. Chem. Soc. Rev 2016, 45, 2656-2693. [PubMed: 27009833] (e)Fielden SDP; Leigh DA; Woltering SL Molecular Knots. Angew. Chem. Int. Ed 2017, 56, 11166-11194. (f)Chakraborty S; Newkome GR Terpyridine-Based Metallosupramolecular Constructs: Tailored Monomers to Precise 2D-Motifs and 3D-Metallocages. Chem. Soc. Rev 2018, 47, 3991-4016. [PubMed: 29594272] (g)Zhang D; Ronson TK; Nitschke JR Functional Capsules via Subcomponent Self-Assembly. Acc. Chem. Res 2018, 51, 2423-2436. [PubMed: 30207688] (h)Jing X; He C; Zhao L; Duan C Photochemical Properties of Host-Guest Supramolecular Systems with Structurally Confined Metal-Organic Capsules. Acc. Chem. Res 2019, 52, 100109. [PubMed: 30586276] (i)Sepehrpour H; Fu W; Sun Y; Stang PJ Biomedically Relevant SelfAssembled Metallacycles and Metallacages. J. Am. Chem. Soc 2019, 141, 14005-14020. [PubMed: 31419112]

(11) (a). Xie TZ; Guo K; Guo Z; Gao WY; Wojtas L; Ning GH; Huang M; Lu X; Li JY; Liao SY; Chen YS; Moorefield CN; Saunders MJ; Cheng SZ; Wesdemiotis C; Newkome GR Precise Molecular Fission and Fusion: Quantitative Self-Assembly and Chemistry of a Metallo-Cuboctahedron. Angew. Chem. Int. Ed 2015, 54, 9224-9229.(b)Fujita D; Ueda Y; Sato S; Mizuno N; Kumasaka T; Fujita M Self-Assembly of Tetravalent Goldberg Polyhedra from 144 Small Components. Nature 2016, 540, 563-566. [PubMed: 30905932] (c)Danon JJ; Kruger A; Leigh DA; Lemonnier JF; Stephens AJ; Vitorica-Yrezabal IJ; Woltering SL Braiding a molecular knot with eight crossings. Science 2017, 355, 159-162. [PubMed: 28082585] (d)Wang H; Liu CH; Wang K; Wang M; Yu H; Kandapal S; Brzozowski R; Xu B; Wang M; Lu S; Hao XQ; Eswara P; Nieh MP; Cai J; Li X J. Am. Chem. Soc 2019, 141, 16108-16116. [PubMed: 31509694]

(12) (a). Kishi N; Li Z; Yoza K; Akita M; Yoshizawa M An $\mathrm{M}_{2} \mathrm{~L}_{4}$ Molecular Capsule with an Anthracene Shell: Encapsulation of Large Guests up to $1 \mathrm{~nm}$. J. Am. Chem. Soc 2011, 133, 11438-11441. [PubMed: 21707060] (b)Li K; Zhang L-Y; Yan C; Wei S-C; Pan M; Zhang L; Su C-Y Stepwise Assembly of $\mathrm{Pd}_{6}\left(\mathrm{RuL}_{3}\right)_{8}$ Nanoscale Rhombododecahedral Metal-Organic Cages via Metalloligand Strategy for Guest Trapping and Protection. J. Am. Chem. Soc 2014, 136, 4456-4459. [PubMed: 24611560] (c)Cullen W; Misuraca MC; Hunter CA; Williams NH; Ward MD Highly Efficient Catalysis of the Kemp Elimination in the Cavity of a Cubic Coordination Cage. Nat. Chem 2016, 8, 231-236. [PubMed: 26892554] (d)Cai L-X; Li S-C; Yan D-N; Zhou L-P; Guo F; Sun Q-F Water-Soluble Redox-Active Cage Hosting Polyoxometalates for Selective Desulfurization Catalysis. J. Am. Chem. Soc 2018, 140, 4869-4876. [PubMed: 29534562] (e)Howlader P; Mondal B; Purba PC; Zangrando E; Mukherjee PS Self-Assembled Pd(II) Barrels as Containers for Transient Merocyanine Form and Reverse Thermochromism of Spiropyran. J. Am. Chem. Soc 2018, 140, 7952-7960. [PubMed: 29874066]

(13). Chakrabarty R; Mukherjee PS; Stang PJ Supramolecular Coordination: Self-Assembly of Finite Two- and Three-Dimensional Ensembles. Chem. Rev 2011, 111, 6810-6918. [PubMed: 21863792]

(14) (a). De Greef TFA; Smulders MMJ; Wolffs M; Schenning APHJ; Sijbesma RP; Meijer EW Supramolecular Polymerization. Chem. Rev 2009, 109, 5687-5754. [PubMed: 19769364] (b)Yang L; Tan X; Wang Z; Zhang X Supramolecular Polymers: Historical Development, Preparation, Characterization, and Functions. Chem. Rev 2015, 115, 7196-7239. [PubMed: 25768045] (c)Yu G; Jie K; Huang F Supramolecular Amphiphiles Based on Host-Guest Molecular Recognition Motifs. Chem. Rev 2015, 115, 7240-7303. [PubMed: 25716119]

(15) (a). Lee CY; Farha OK; Hong BJ; Sarjeant AA; Nguyen ST; Hupp JT Light-Harvesting MetalOrganic Frameworks (MOFs): Efficient Strut-to-Strut Energy Transfer in Bodipy and PorphyrinBased MOFs. J. Am. Chem. Soc 2011, 133, 15858-15861. [PubMed: 21916479] (b)Kent CA; Liu D; Ma L; Papanikolas JM; Meyer TJ; Lin W Light Harvesting in Microscale Metal-Organic Frameworks by Energy Migration and Interfacial Electron Transfer Quenching. J. Am. Chem. Soc 2011, 133, 12940-12943. [PubMed: 21776996] (c)Son HJ ; Jin S; Patwardhan S; Wezenberg SJ; Jeong NC; So M; Wilmer CE; Sarjeant AA; Schatz GC; Snurr RQ; Farha OK ; Wiederrecht GP; Hupp JT Light-Harvesting and Ultrafast Energy Migration in Porphyrin-Based MetalOrganic Frameworks. J. Am. Chem. Soc 2013, 135, 862-869. [PubMed: 23249338] (d)Williams DE; Rietman JA; Maier JM; Tan R; Greytak AB; Smith MD; Krause JA; Shustova NB Energy 
Transfer on Demand: Photoswitch-Directed Behavior of Metal-Porphyrin Frameworks. J. Am. Chem. Soc 2014, 136, 11886-11889. [PubMed: 25116646]

(16). Huang CB; Xu L; Zhu JL; Wang YX; Sun B; Li X; Yang HB Real-Time Monitoring the Dynamics of Coordination-Driven Self-Assembly by Fluorescence-Resonance Energy Transfer. J. Am. Chem. Soc 2017, 139, 9459-9462. [PubMed: 28661660]

(17) (a). Li Z; Kishi N; Hasegawa K; Akita M; Yoshizawa M Highly Fluorescent $\mathrm{M}_{2} \mathrm{~L}_{4}$ Molecular Capsules with Anthracene Shells. Chem. Commun 2011, 47, 8605-8607.(b)Yan X; Wei P; Liu Y; Wang M; Chen C; Zhao J; Li G; Saha ML; Zhou Z; An Z; Li X; Stang PJ Endo- and ExoFunctionalized Tetraphenylethylene $\mathrm{M}_{12} \mathrm{~L}_{24}$ Nanospheres: Fluorescence Emission inside a Confined Space. J. Am. Chem. Soc 2019, 141, 9673-9679. [PubMed: 31125220]

(18) (a). Yan X; Cook TR; Wang P; Huang F; Stang PJ Highly emissive platinum(II) metallacages. Nat. Chem 2015, 7, 342-348. [PubMed: 25803473] (b)Yan X; Wang M; Cook TR; Zhang M; Saha ML; Zhou Z; Li X; Huang F; Stang PJ Light-Emitting Super-structures with Anion Effect: Coordination-Driven Self-Assembly of Pure Tetraphenylethylene Metallacycles and Metallacages. J. Am. Chem. Soc 2016, 138, 4580-4588. [PubMed: 26982213] (c)Yu G; Zhang M; Saha ML; Mao Z; Chen J; Yao Y; Zhou Z; Liu Y; Gao C; Huang F; Chen X; Stang PJ Antitumor Activity of a Unique Polymer That Incorporates a Fluorescent Self-Assembled Metallacycle. J. Am. Chem. Soc 2017, 139, 15940-15949. [PubMed: 29019660] (d)Lu C; Zhang M; Tang D; Yan X; Zhang Z; Zhou Z; Song B; Wang H; Li X; Yin S; Sepehrpour H; Stang PJ Fluorescent Metallacage-Core Supramolecular Polymer Gel Formed by Orthogonal Metal Coordination and Host-Guest Interactions. J. Am. Chem. Soc 2018, 140, 7674-7680. [PubMed: 29856215]

(19) (a). Shustova NB; McCarthy BD; Dinca M Turn-On Fluorescence in Tetraphenylethylene-Based Metal-Organic Frameworks: An Alternative to Aggregation-Induced Emission. J. Am. Chem. Soc 2011, 133, 20126-20129. [PubMed: 22074054] (b)Zhang M; Feng G; Song Z; Zhou YP; Chao HY; Yuan D; Tan TT; Guo Z; Hu Z; Tang AZ; Liu B; Zhao D Two-Dimensional Metal-Organic Framework with Wide Channels and Responsive Turn-On Fluorescence for the Chemical Sensing of Volatile Organic Compounds. J. Am. Chem. Soc 136, 7241-7244. [PubMed: 24824627] (c)Zhao J; Yang D; Zhao Y; Yang X-J; Wang Y-Y; Wu B Anion-Coordination-Induced Turn-On Fluorescence of an Oligourea-Functionalized Tetraphenylethene in a Wide Concentration Range. Angew. Chem. Int. Ed 2014, ;53, 6632-6636.(d)Sinha N; Stegemann L; Tan TTY; Doltsinis NL; Strassert AA; Hahn FE Turn-On Fluorescence in Tetra-NHC Ligands by Rigidification through Metal Complexation: An Alternative to Aggregation-Induced Emission. Angew. Chem. Int. Ed 2017, 56, 2785-2789.(e)Yin GQ; Wang H; Wang XQ; Song B; Chen LJ; Wang L; Hao XQ; Yang HB; Li X Self-Assembly of Emissive Supramolecular Rosettes with Increasing Complexity Using Multitopic Terpyridine Ligands. Nat. Commun 2018, 9, 567. [PubMed: 29422628] (f)Liu N; Lin T; Wu M; Luo HK; Huang SL; Hor TSA Suite of Organoplatinum(II) Triangular Metallaprism: Aggregation-Induced Emission and Coordination Sequence Induced Emission Tuning. J. Am. Chem. Soc 2019, 141, 9448-9452. [PubMed: 31150578] (g)Li Y; An YY; Fan JZ; Liu XX; Li X; Hahn FE; Wang YY; Han YF Strategy for the Construction of Diverse Poly-NHCDerived Assemblies and Their Photoinduced Transformations. Angew. Chem. Int. Ed 2019, 58, DOI: 10.1002/anie.201912322.

(20) (a). Hong Y; Lam JWY; Tang BZ Aggregation-Induced Emission. Chem. Soc. Rev 2011, 40, 5361-5388. [PubMed: 21799992] (b)Mei J; Leung NL; Kwok RT; Lam JW; Tang BZ Aggregation-Induced Emission: Together We Shine, United We Soar! Chem. Rev 2015, 115 , 11718-11940. [PubMed: 26492387]

(21) (a). Yan X; Wang H; Hauke CE; Cook TR; Wang M; Saha ML; Zhou Z; Zhang M; Li X; Huang F; Stang PJ A Suite of Tetraphenylethylene-Based Discrete Organoplatinum(II) Metallacycles: Controllable Structure and Stoichiometry, Aggregation-Induced Emission, and Nitroaromatics Sensing. J. Am. Chem. Soc2014, 137, 15276-15286.(b)Zhang M; Saha ML; Wang M; Zhou Z; Song B; Lu C; Yan X; Li X; Huang F; Yin S; Stang PJ Multicomponent Platinum(II) Cages with Tunable Emission and Amino Acid Sensing. J. Am. Chem. Soc 2017, 139, 5067-5074. [PubMed: 28332834]

(22) (a). Zhang M; Yin S; Zhang J; Zhou Z; Saha ML; Lu C; Stang PJ Metallacycle-cored supramolecular assemblies with tunable fluorescence including white-light emission. Proc. Natl. Acad. Sci U. S. A 2017, 114, 3044-3049. [PubMed: 28265080] (b)Sun Y; Yao Y; Wang H; Fu 
W; Chen C; Saha ML; Zhang M; Datta S; Zhou Z; Yu H; Li X; Stang PJ Self-Assembly of Metallacages into Multidimen-sional Suprastructures with Tunable Emissions. J. Am. Chem. Soc 2018, 140, 12819-12828. [PubMed: 30212221]

(23) (a). Zhang Z; Zhao Z; Hou Y; Wang H; Li X; He G; Zhang M Aqueous Platinum(II)-Cage-Based Light-Harvesting System for Photocatalytic Cross-Coupling Hydrogen Evolution Reaction. Angew. Chem., Int. Ed 2019, 58, 8862-8866.(b)Acharyya K; Bhattacharyya S; Sepehrpour H; Chakraborty S; Lu S; Shi B; Li X; Mukherjee PS; Stang PJ Self-Assembled Fluorescent Pt(II) Metallacycles as Artificial Light-Harvesting Systems. J. Am. Chem. Soc 2018, 141, 1456514569.

(24). Sagara Y; Yamane S; Mitani M; Weder C; Kato T Mechanoresponsive Luminescent Molecular Assemblies: An Emerging Class of Materials. Adv. Mater 2016, 28, 1073-1095. [PubMed: 26461848]

(25) (a). Yuan H; Wang K; Yang K; Liu B; Zou B Luminescence Properties of Compressed Tetraphenylethene: The Role of Intermolecular Interactions. J. Phys. Chem. Lett 2014, 5, 29682973. [PubMed: 26278244] (b)Ma Z; Wang Z; Meng X; Ma Z; Xu Z; Ma Y; Jia X A Mechanochromic Single Crystal: Turning Two Color Changes into a Tricolored Switch. Angew. Chem., Int. Ed 2016, 55, 519-522.(c)Qiu Z; Zhao W; Cao M; Wang Y; Lam JWY; Zhang Z; Chen X; Tang BZ Dynamic Visualization of Stress/Strain Distribution and Fatigue Crack Propagation by an Organic Mechanoresponsive AIE Luminogen. Adv. Mater. 2018, 30, No. 1803924.

(26) (a). Zhang Q; Su J; Feng D; Wei Z; Zou X; Zhou HC Piezofluorochromic Metal-Organic Framework: A Microscissor Lift. J. Am. Chem. Soc. 2015, 137, 10064-10067. [PubMed: 26214704] (b)Chen CX; Wei ZW; Fan YN; Su PY; Ai YY; Qiu QF; Wu K; Yin SY; Pan M; Su CY Visualization of Anisotropic and Stepwise Piezo-fluorochromism in an MOF Single Crystal. Chem. 2018, 4, 2658-2669.

(27). Liu Y; Zeng Q; Zou B; Liu Y; Xu B; Tian W Piezochromic Luminescence of Donor-Acceptor Cocrystals: Distinct Responses to Anisotropic Grinding and Isotropic Compression. Angew. Chem, Int. Ed 2018, 57, 15670-15674.

(28). Dewaele A; Loubeyre P; Occelli F; Marie O; Mezouar M Toroidal Diamond Anvil Cell for Detailed Measurements under Extreme Static Pressures. Nat. Commun 2018, 9, 2913. [PubMed: 30046093]

(29) (a). Tang JH; Sun Y; Gong ZL; Li ZY; Zhou Z; Wang H; Li X; Saha ML; Zhong YW; Stang PJ Temperature-Responsive Fluorescent Organoplatinum(II) Metallacycles. J. Am. Chem. Soc 2018, 140, 7723-7729. [PubMed: 29782153] (b)Sun Z-B; Liu J-K; Yuan D-F; Zhao Z-H; Zhu X-Z; Liu D-H; Peng Q; Zhao C-H 2,2' -Diamino-6,6' -diboryl-1,1' -binaphthyl: A Versatile Building Block for Temperature-Dependent Dual Fluorescence and Switchable Circularly Polarized Luminescence. Angew. Chem., Int. Ed 2019, 58, 4840-4846.

(30). The emission response of cages $\mathbf{4 a}$ and $\mathbf{4 b}$ as solid powders to the temperature was also collected and is shown in Figure S62. 
(a)

(b)

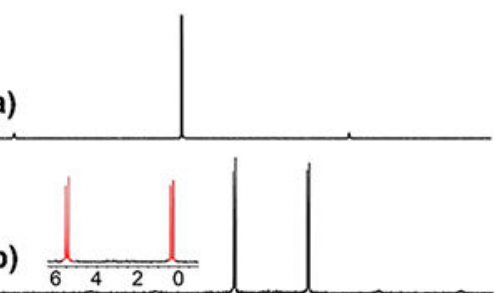

(c)

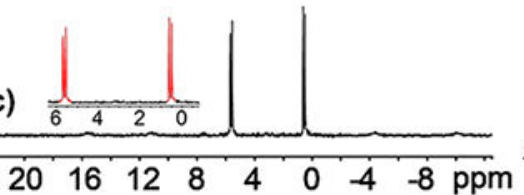

(d)
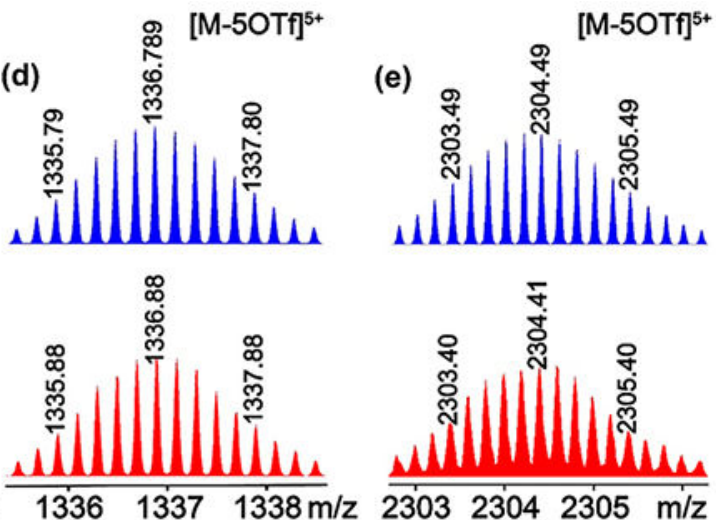

(f)<smiles>CCC(C)C</smiles>

$\mathrm{H}_{4}$

(g)

$\mathrm{H}_{1}$<smiles>C=CC=CC=C</smiles>

$\mathrm{H}_{4}$

(h)

$\mathrm{H}_{5}$
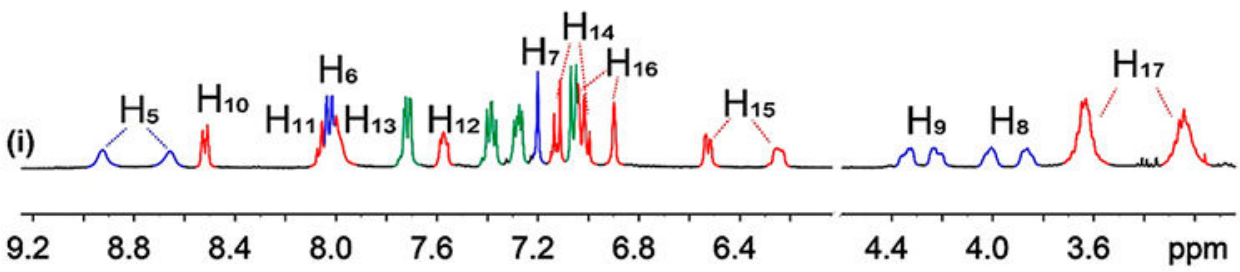

Figure 1.

Partial ${ }^{31} \mathrm{P}\left\{{ }^{1} \mathrm{H}\right\}$ NMR spectra (121.4 MHz, $\mathrm{CD}_{3} \mathrm{COCD}_{3}, 295 \mathrm{~K}$ ) of (a) $\mathbf{3}$, (b) $\mathbf{4 a}$, and (c) $\mathbf{4 b}$. Experimental (red) and calculated (blue) ESI-TOF MS spectra of (d) $4 \mathbf{a}$ and (e) $\mathbf{4 b}$ : [M 5OTf $]^{5+}$. Partial ${ }^{1} \mathrm{H}$ NMR spectra (400 MHz, $\mathrm{CD}_{3} \mathrm{COCD}_{3}, 295 \mathrm{~K}$ ) of (f) $\mathbf{2 a},(\mathrm{g}) \mathbf{4 a}$, (h) $\mathbf{2 b}$, and (i) $\mathbf{4 b}$. The labeling of different protons is indicated in Scheme 1. 
(a)

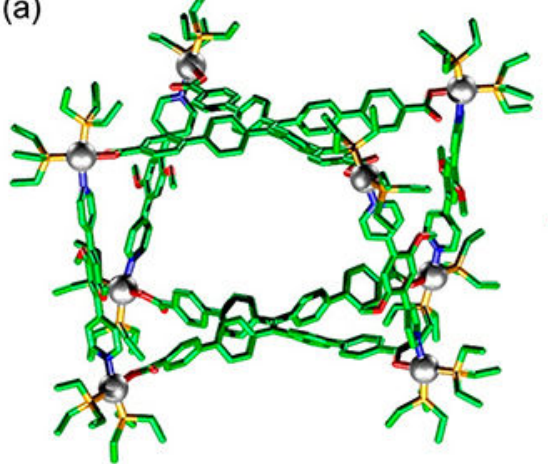

(b)

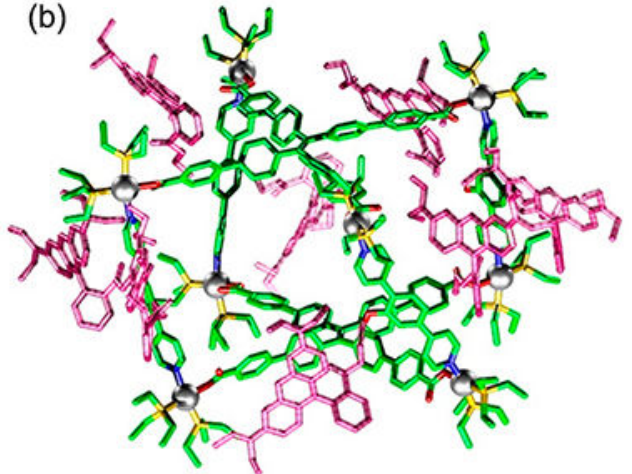

Figure 2.

Optimized molecular structures of cages (a) $\mathbf{4 a}$ and (b) $\mathbf{4 b}$ by DFT calculations. The hydrogen atoms were omitted for clarity. Pt atoms were represented by silver balls, and the pillars and faces were represented by sticks. 

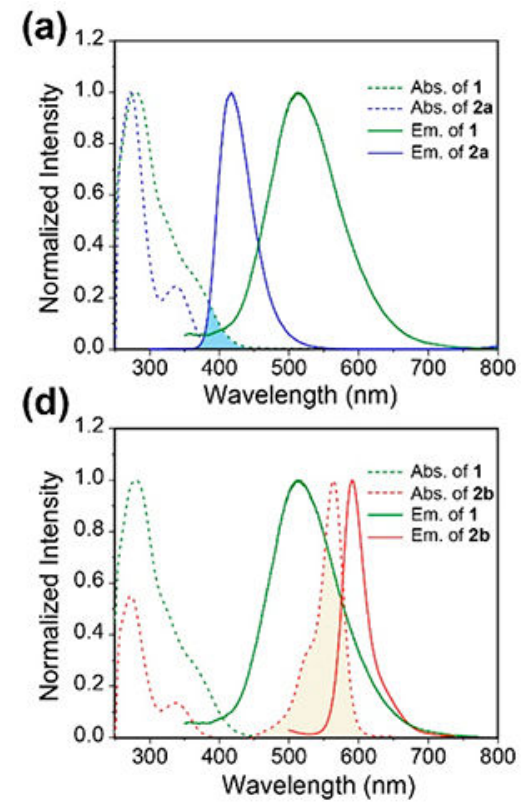

(b)

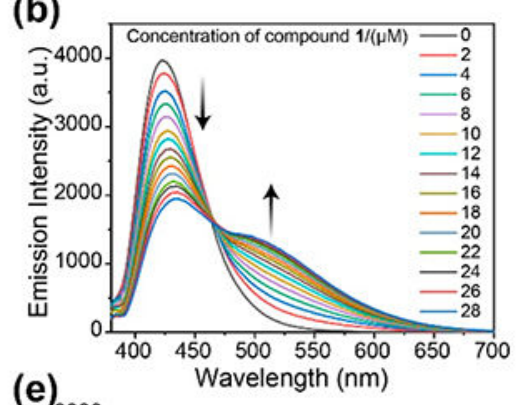

(e)

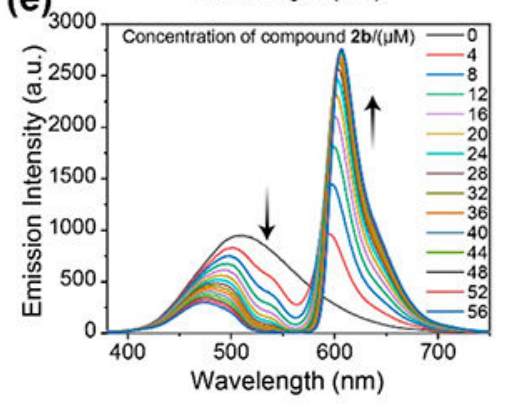

(c)

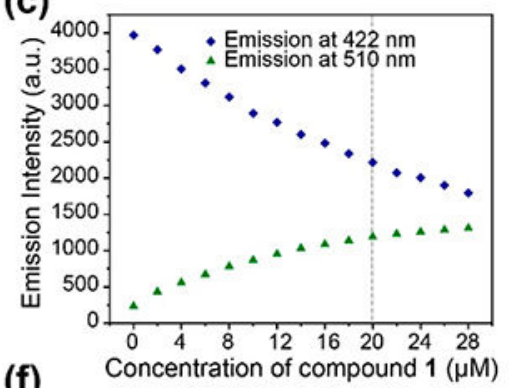

(f)

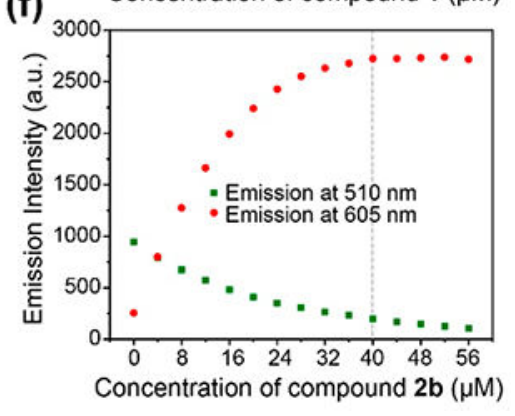

Figure 3.

(a) Normalized absorption and emission spectra of compounds $\mathbf{1}$ and 2a in DMSO. (b) Fluorescence spectra of compound $2 \mathbf{a}(c=40.0 \mu \mathrm{M})$ and $\mathbf{3}(c=80.0 \mu \mathrm{M})$ in a mixture of DMSO and water $(v / v=10 / 1)$ with different concentrations of compound 1. (c) Fluorescent intensity changes in (b) at 422 and $510 \mathrm{~nm}$. (d) Normalized absorption and emission spectra of compounds $\mathbf{1}$ and $\mathbf{2 b}$ in DMSO. (e) Fluorescence spectra of compounds $\mathbf{1}(c=20.0 \mu \mathrm{M})$ and $\mathbf{3}(c=80.0 \mu \mathrm{M})$ in a mixture of DMSO and water $(\mathrm{v} / \mathrm{v}=10 / 1)$ with different concentrations of compound $\mathbf{2 b}$. (f) Fluorescence intensity changes in (e) at 510 and 605 $\mathrm{nm}$. The dashed lines in (c) and (f) indicate the achievement of the stoichiometries of the metallacages. $\lambda_{\mathrm{ex}}=340 \mathrm{~nm}$. 
(a)

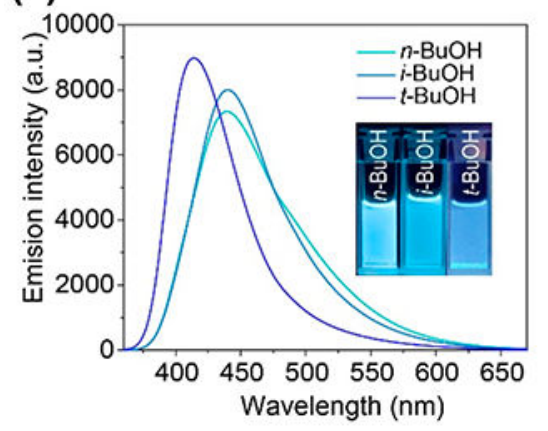

(b)

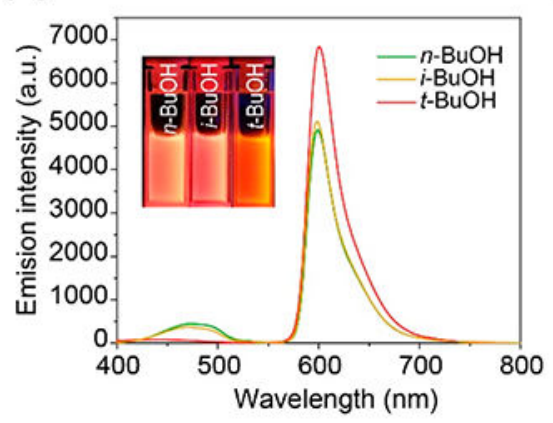

(c)

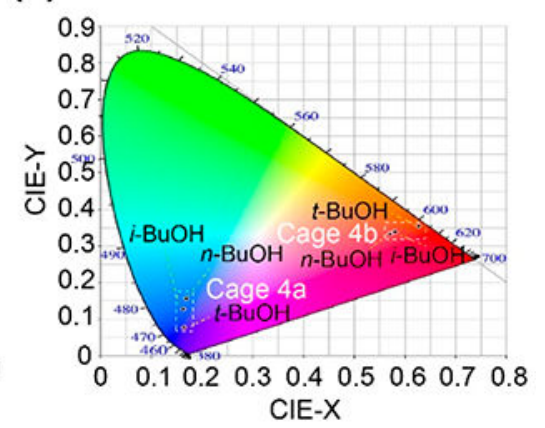

Figure 4.

Fluorescence spectra of (a) cage $\mathbf{4 a}$ and (b) cage $\mathbf{4 b}$ and (c) their corresponding CIE chromaticity coordinates in different alcohols $\left(\lambda_{\mathrm{ex}}=340 \mathrm{~nm}, c=10.0 \mu \mathrm{M}\right)$. Insets: photographs of cages $\mathbf{4 a}$ and $\mathbf{4 b}$ upon excitation at $365 \mathrm{~nm}$ using a UV lamp at $298 \mathrm{~K}$. 
(a)

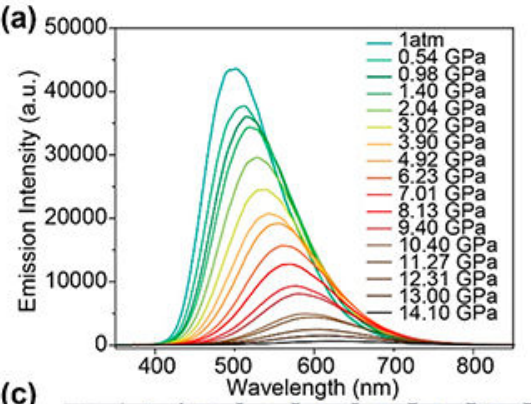

(c)

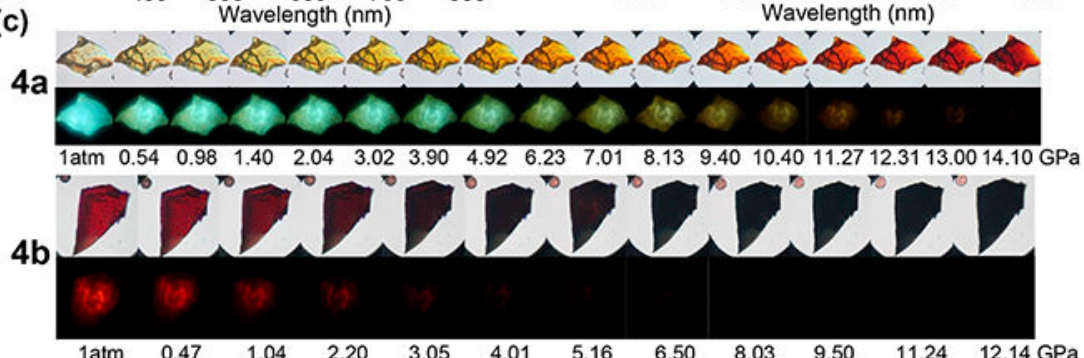

(b)

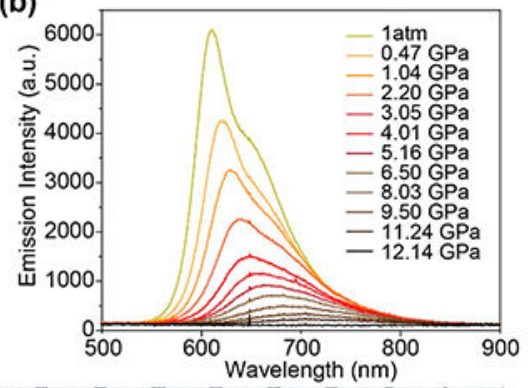

Figure 5.

Emission spectra of cages (a) $\mathbf{4 a}$ and (b) $\mathbf{4 b}$ under different pressures and (c) their optical (white background) and fluorescent images (dark background). 

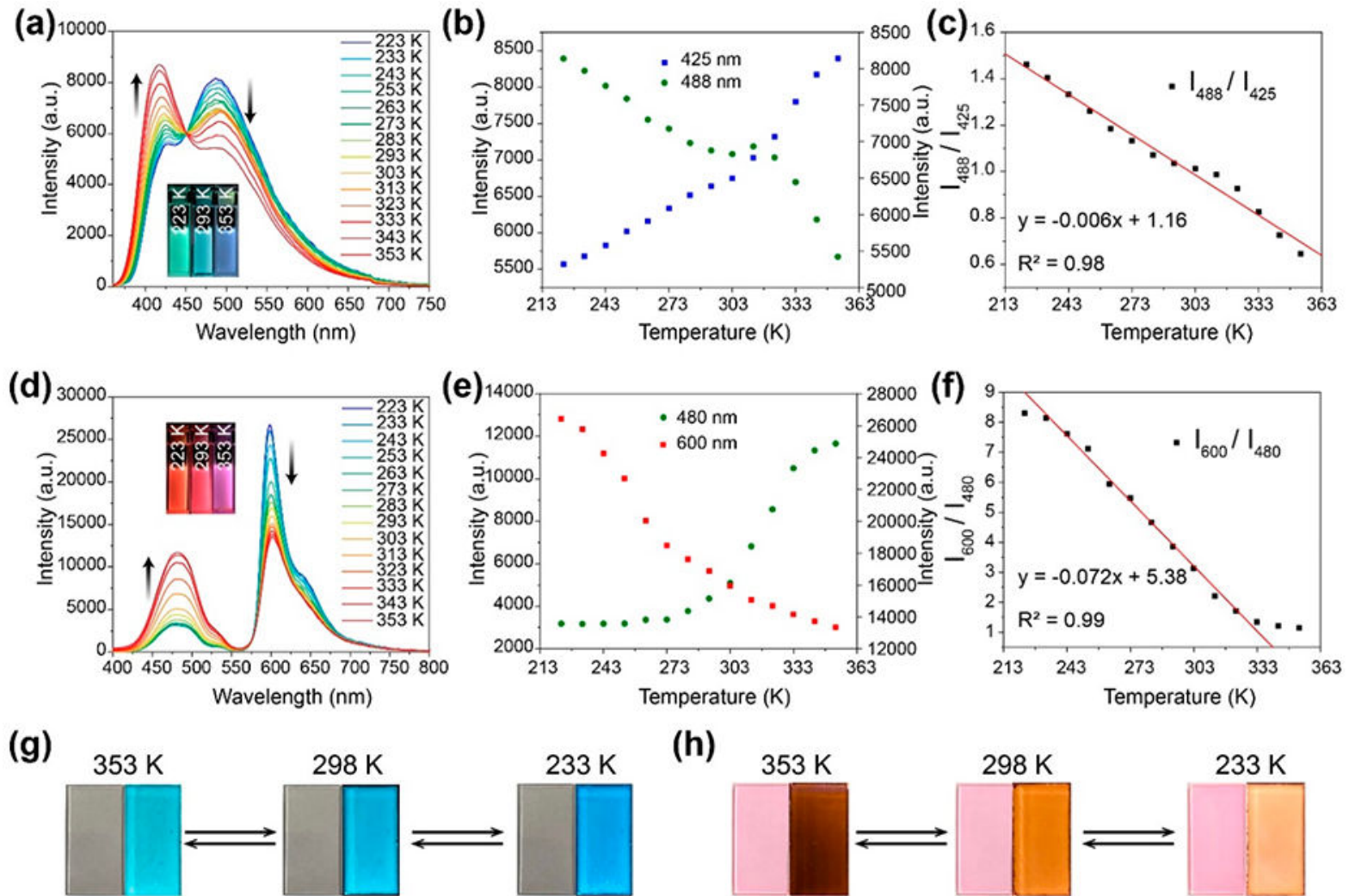

(h)

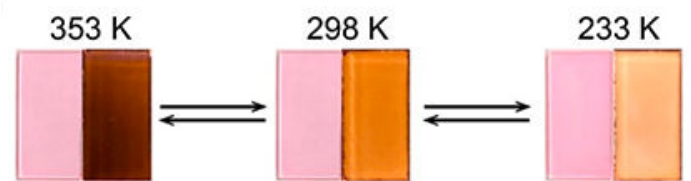

Figure 6.

(a) Fluorescence spectra of cage $4 a(c=10.0 \mu \mathrm{M})$ in DMF at different temperatures. (b) Fluorescence intensity changes in cage $4 \mathbf{a}$ at 425 and $488 \mathrm{~nm}$. (c) Plots of $I_{488} / I_{425}$ versus temperature. (d) Fluorescence spectra of cage $4 \mathbf{b}(c=10.0 \mu \mathrm{M})$ in DMF at different temperatures. (e) Fluorescence intensity changes of cage $\mathbf{4 b}$ at 480 and $600 \mathrm{~nm}$. (f) Plots of $I_{488} / I_{425}$ versus temperature. Optical and fluorescent photographs of (g) $\mathbf{4 a}$ and (h) $\mathbf{4 b}$ at different temperatures. 


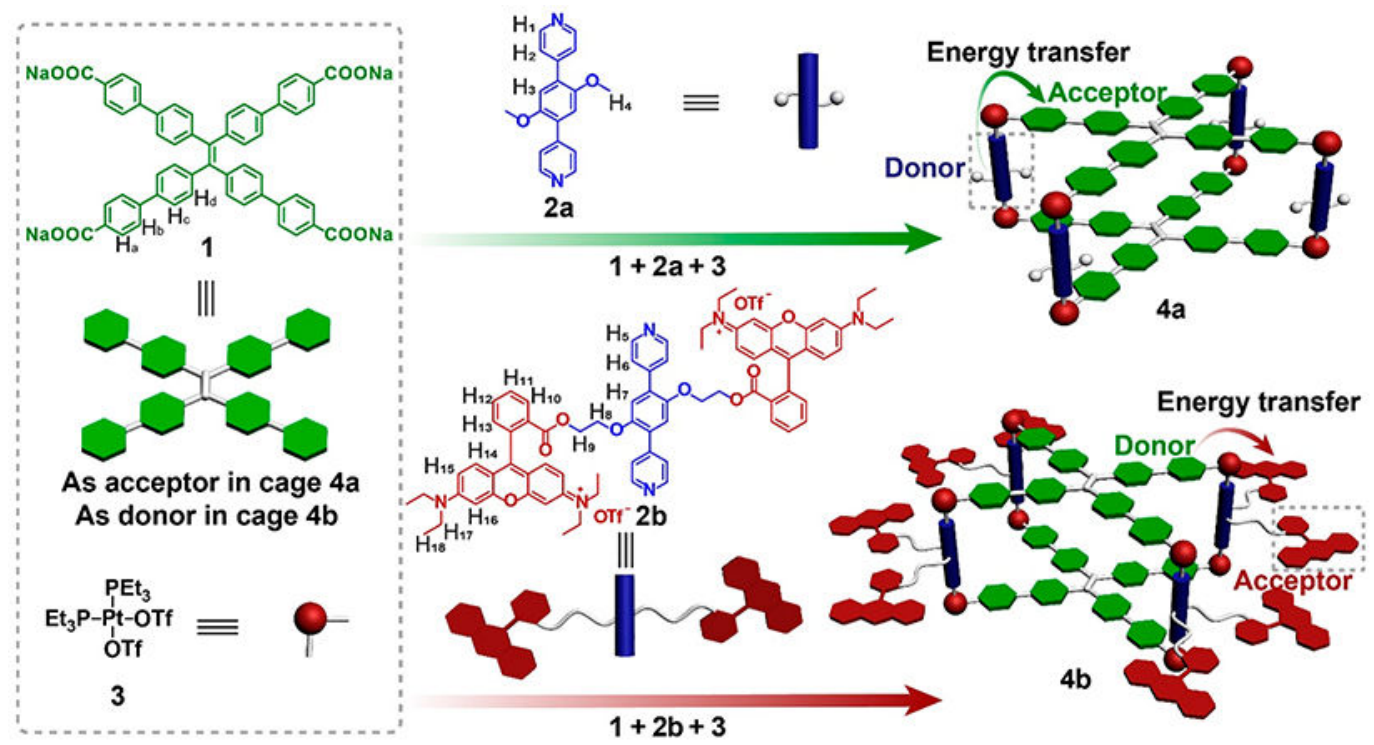

Scheme 1.

Self-Assembly of Metallacages 4a and $4 \mathrm{~b}$ with Reverse FRET Behavior 